\title{
APRENDIZAGENS PROFISSIONAIS DE PROFESSORES DOS PRIMEIROS ANOS PARTICIPANTES NUM ESTUDO DE AULA
}

\author{
Mónica Baptista \\ João Pedro da Ponte"* \\ Isabel Velez ${ }^{* *}$ \\ Estela Costa ${ }^{* \cdots *}$
}

RESUMO: O estudo de aula é um processo formativo que leva os professores a refletirem, através de um trabalho eminentemente colaborativo, sobre a sua prática profissional. Trata-se de uma experiência que envolve três momentos principais: planejamento, observação da aula, e reflexão pós-aula e seguimento. O seu objetivo é criar condições para uma maior compreensão dos processos de raciocínio dos alunos por parte dos professores e, assim, contribuir para o seu desenvolvimento profissional. Neste artigo, analisamos as possibilidades formativas dos estudos de aula no que se refere às aprendizagens profissionais dos professores relativas à prática letiva, com enfoque na seleção de tarefas e na análise do raciocínio dos alunos, bem como à sua visão da colaboração e reflexão profissional. Para isso, seguiu-se uma metodologia qualitativa e interpretativa, tendo por base a observação participante. O estudo de aula que apresentamos decorreu num Agrupamento de Escolas, situado numa zona rural, e envolveu cinco professoras dos primeiros anos e uma equipe do Instituto de Educação. Os resultados reforçam a ideia de que os estudos de aula podem proporcionar aos professores um olhar mais atento sobre a natureza das tarefas a propor em sala de aula e levá-los a valorizar mais os processos de raciocínio dos seus alunos. Além disso, este trabalho evidencia o contributo do estudo de aula para o desenvolvimento de um trabalho colaborativo entre professores e para a sua valorização da reflexão.

Palavras-Chave: Estudo de aula. Desenvolvimento profissional. Tarefas. Colaboração. Reflexão.

\footnotetext{
* Doutora em Educação pela Universidade de Lisboa e Professora auxiliar na Universidade de Lisboa. Email: mbaptista@ie.ul.pt

* * Doutor em Educação pela Universidade de Lisboa; Agregado em Educação pela Universidade de Lisboa e Professor Catedrático na Universidade de Lisboa. Email: jpponte@ie.ul.pt

*** Mestre e Doutoranda em Educação pela Universidade de Lisboa. Email: velez@campus.ul.pt **** Doutora em Educação pela Universidade de Lisboa e Professora auxiliar na Universidade de Lisboa. Email: ecosta@ie.ul.pt
} 


\title{
PROFESSIONAL TEACHERS OF EARLY EDUCATION LEARNING AND TAKING PART OF A CLASS STUDY
}

\begin{abstract}
The study of an instructional class is a process of schooling that helps teachers to think through an eminent and collaborative work and their professional career. That study deals with the experience which involves three mostly important events: planning, observation of the instructional class and questioning pos-classroom and follow-ups. Its objective is to create conditions for a bigger comprehension of the processes which involve reasoning from students motivated by teachers and, on that manner, the report contributes to the professional development. On this article, we analyze the schooling possibilities of studies for the classroom due respect to teachers' forms of learning skills related to their elective practice with the focus on selecting tasks along with students forms of reasoning as well as their professional vision of collaboration and the importance of questioning. This report follows a qualitative and interpretative methodology having on the background the actor as a basis of observation. The study of the instructional class we present takes place on a Given Number of Schools which can be located in a farming area in a rural zone and it involved a crew of 5 teachers from the $5^{\text {th }}$ primary years from the Institute of Education. The results reinforce the idea that the studies of schooling class provide teachers with an attentive look over the nature of tasks to be suggested in the classroom and teachers help students to attribute more values over the tasks and the reasoning of their pupils. Thus, this work sets light over the contribution of the schooling class for the development of a collaborative work between teachers for its questioning.
\end{abstract}

Keywords: The Study of Schooling Class. Professional Development. Tasks. Collaboration. Reasoning.

\section{INTRODUÇÃo}

O estudo de aula ${ }^{1}$ corresponde a uma modalidade de formação de professores centrada na sua própria prática profissional e concretizada através de dinâmicas colaborativas e reflexivas enraizadas na cultura profissional dos docentes. Essa modalidade teve origem no Japão no início do século XX, conheceu grande divulgação nos Estados Unidos da América na última década e tem vindo a atrair o interesse de educadores e investigadores de todo o mundo. Assim, por exemplo, Hart, Alston e Murata (2011), num livro recente, apresentam os estudos de aula em diversas das suas variantes em diferentes contextos, apresentando investigações de referência sobre o desenvolvimento desses estudos em diversos países. 
Esse processo formativo contempla três momentos principais (MURATA, 2011). O primeiro envolve o planejamento de uma aula e começa com a formulação de uma questão de interesse comum por um grupo de professores a observar nessa aula. A partir dessa questão, relacionada com as aprendizagens dos seus alunos, os professores planejam cuidadosamente em conjunto uma aula tendo em conta o programa da disciplina, os materiais e recursos disponíveis, alguma informação adicional que possam obter, por exemplo, sobre os conhecimentos e as dificuldades dos alunos. Segue-se o momento da observação, em que a aula em questão é lecionada por um dos professores, assumindo os restantes o papel de observadores atentos, em especial ao modo como os alunos resolvem as tarefas propostas, às estratégias que usam e às dificuldades que manifestam. Os professores tomam notas pessoais e podem ser feitos registros de vídeo e áudio.

Posteriormente, terminada a aula, segue-se o terceiro momento, de reflexão e seguimento. A aula é então objeto de análise dos professores, tendo em conta a questão de interesse comum formulada no início do processo. Ao contrário de muitos outros processos de observação, que se centram no desempenho do professor, aqui o centro da atenção são os alunos. Essa análise pode originar a reformulação do plano da aula, alterando a estratégia a seguir, os materiais a usar, as tarefas a propor, as questões a colocar aos alunos, etc. Com essas mudanças, a aula é muitas vezes lecionada mais tarde por outro professor a outros alunos, num ciclo que pode repetir-se várias vezes (LEWIS, PERRY \& HURD, 2009; MURATA, 2011). O conjunto dessas três etapas constitui um processo de aprendizagem profissional, que leva os professores a aprofundar o seu conhecimento sobre a aprendizagem dos alunos e o modo de promovê-la na sala de aula.

Neste artigo analisamos as possibilidades formativas dos estudos de aula no que se refere às aprendizagens profissionais dos professores relativas à prática letiva, bem como à sua visão da colaboração e da reflexão profissional. Para isso, apresentamos um estudo de aula realizado numa escola portuguesa, com cinco professoras do $1^{\circ}$ ciclo do ensino básico ${ }^{2}$.

\section{ESTUDOS DE AULA E APRENDIZAGENS PROFISSIONAIS DOS PROFESSORES}

As aprendizagens profissionais dos professores envolvidos em estudos de aula têm sido foco de várias investigações. Dado o 
objetivo deste artigo, fazemos uma breve revisão dos resultados obtidos em pesquisas anteriores relativas às tarefas que os professores selecionam para a sala de aula, à atenção que dão ao raciocínio dos alunos, às suas práticas de colaboração e à sua reflexão sobre a prática.

Tarefas propostas. Um dos aspectos destacados em várias pesquisas refere-se à natureza das tarefas propostas pelos professores na sala de aula, tendo sido assinaladas mudanças no sentido de tarefas mais favorecedoras da aprendizagem. Por exemplo, os resultados de uma investigação de Doig, Groves e Fujii (2011) mostram que uma professora das primeiras séries do ensino fundamental passou a defender que as tarefas a propor devem ter um caráter desafiante, permitindo que os alunos as resolvam por vários processos. Também Saito et al. (2006), noutra pesquisa com professores do ensino fundamental ao ensino médio, destacam que um estudo de aula permitiu que os professores passassem a realizar aulas com uma naturezamais exploratória.

Resultados semelhantes foram obtidos nas pesquisas realizadas por Corcoran e O'Reilly (2011), Fernandez e Zilliox (2011) e Murata et al. (2012). Na pesquisa de Corcoran e O'Reilly (2011) os investigadores concluem que os professores participantes passaram a incluir nos seus planejamentos tarefas mais desafiantes para os alunos e que o estudo de aula levou-os a conhecer diferentes perspectivas e ideias sobre o desenvolvimento de tarefas e sobre o modo de realizá-las na sala de aula. Igualmente, na pesquisa de Fernandez e Zilliox (2011), os resultados revelam que os professores envolvidos, do ensino fundamental e do médio, começaram a incluir nos seus planejamentos tarefas inovadoras, que possibilitaram aos alunos assumir um papel mais ativo. Por último, na pesquisa de Murata et al. (2012), os autores registram mudanças na forma como os professores planejaram as suas aulas, tendo verificado que se dispuseram a correr riscos para mudar as práticas e realizar tarefas que implicassem os alunos em resolução de problemas.

Outro aspecto salientado em algumas pesquisas refere-se à seleção das tarefas a realizar na aula observada. Por exemplo, Meyer e Wilkerson (2011) realizaram um estudo de aula com professores da segunda fase do ensino fundamental cujos resultados sugerem três questões fundamentais a ter em consideração na seleção das tarefas a usar: (i) decidir manter ou alterar uma tarefa que se encontra já construída; (ii) antecipar as questões e respostas dos alunos à tarefa; e (iii) discutir o conteúdo da tarefa. Concluem que, de modo geral, a participação em estudos de aula cria nos 
professores propensão para, durante o planejamento das tarefas, adequar o nível de exigência às características dos alunos e propor tarefas mais inovadoras e de cunho exploratório.

Raciocínio dos alunos. Outro campo que também tem sido objeto de atenção da pesquisa relaciona-se com o modo como os professores encaram o raciocínio dos alunos, após a realização de estudos de aula. De um modo geral, verifica-se que os professores valorizam a importância do raciocínio dos seus alunos e alteram as suas práticas como consequência do estudo de aula. Por exemplo, na investigação de Hart e Carriere (2011), que envolveu a participação de professores da $3^{a}$ série, em três ciclos de estudo de aula, os resultados indicam que nas primeiras observações a atenção dos professores recaiu em questões relacionadas com o comportamento dos alunos e a sua organização na sala de aula. No entanto, com o decurso dos ciclos de estudo de aula, o foco de análise passou a ser o raciocínio, a aprendizagem e as dificuldades dos alunos, levando progressivamente os professores a refletir sobre questões que facilitariam sua compreensão e aprendizagem. Pelo seu lado, na pesquisa de Lewis, Perry e Hurd (2009), os resultados indicam que os professores participantes num estudo de aula também passaram a dar mais atenção ao raciocínio dos alunos. Durante a experiência, identificaram alguns fatores que influenciaram as dificuldades dos alunos e, com base nessa reflexão, reviram seus planos de aula, de modo a promover mais eficazmente o raciocínio dos alunos. Resultados idênticos foram também obtidos na pesquisa de Robinson e Leikin (2012). De fato, os investigadores puderam verificar que, ao darem maior relevância ao raciocínio, às dificuldades e à capacidade dos alunos, os professores mudaram a estrutura e natureza de tarefas. Desse modo, várias investigações sugerem que a participação em estudos de aula tende a levar os professores a dar mais importância ao raciocínio, relacionando-o com as características, dificuldades e capacidades dos alunos, o que se refletiu na sua observação e no planejamento de aulas.

Colaboração. O trabalho conjunto entre professores, associado à realização de estudos de aula, indicia uma forte valorização da colaboração profissional, com consequências positivas para o desenvolvimento profissional dos professores envolvidos. $\mathrm{Na}$ verdade, são várias as pesquisas que mostram como, na sequência de participação nesse tipo de experiência, os professores passam a valorizar mais o trabalho colaborativo e empreender mudanças nas suas práticas. Por exemplo, na investigação realizada 
por Robinson e Leikin (2012), desenvolvida durante um ano letivo com professores da $3^{\mathrm{a}}$ à $6^{\mathrm{a}}$ série em Israel, os investigadores concluem que o trabalho colaborativo ajudou os professores a compreenderem a necessidade de alterar as suas práticas e a discutirem soluções, tendo em vista a resolução dos problemas com que se deparavam. Os autores consideram que esse trabalho levou os professores a desenvolverem-se profissionalmente, realçando práticas como a "chuva de ideias" e conceitos como a "compreensão colaborativa" e a "consciência colaborativa" (p. 158). Igualmente, na pesquisa de Burroughs e Luebeck (2010), que envolveu futuros professores do ensino fundamental e médio, os resultados indicam que a participação num estudo de aula levou os participantes a valorizar a oportunidade de colaborar com professores das escolas.

Vários autores referem que a colaboração promove alterações ao nível da discussão, do trabalho em equipe e do planejamento das aulas com colegas. Por exemplo, na pesquisa de Lewis, Perry e Hurd (2009), as mudanças foram particularmente profundas e o trabalho colaborativo tornou-se uma prática habitual. Nesse caso, antes da fase de planejamento houve uma fase prévia de investigação, na qual os professores estudaram documentos curriculares e resolveram e discutiram problemas de Matemática. Segundo os autores, houve mudanças no grupo dos professores participantes (do $1^{\circ}, 2^{\circ}$ e $3^{\circ}$ ciclos), nomeadamente na forma como trabalhavam em conjunto. Os autores referem que a equipe começou a trabalhar habitualmente de forma colaborativa e que, seis anos depois, continuavam a realizar estudos de aula por iniciativa própria.

$\mathrm{Na}$ pesquisa de Puchner e Taylor (2006), os resultados sugerem que a realização de estudos de aula, em escolas dos primeiros anos e na educação pré-escolar, nos Estados Unidos, promoveu mudanças relacionadas com a autonomia e o isolamento dos professores, tendo-se conseguido criar um ambiente de colaboração. Nessa pesquisa, os professores participantes consideraram que o trabalho realizado permitiu mudar completamente o tipo de discussão sobre o ensino e a aprendizagem. Assim, diversas investigações realizadas sublinham que a experiência de estudo de aula promoveu a colaboração, favorecendo a troca de ideias, o apoio e a ajuda entre os vários professores envolvidos.

Reflexão. Os resultados de diversas pesquisas também sugerem que os estudos de aula têm capacidade de influenciar o desenvolvimento da capacidade reflexiva dos professores. Por exemplo, na pesquisa 
de Sack e Vasquez (2011), que envolveu professores dos quatro primeiros anos do ensino fundamental, nos Estados Unidos, os resultados indicam que a reflexão sobre a prática proporcionada pelo estudo de aula foi fundamental para a promoção da prática de ensino. Outro aspecto interessante referido pelos professores participantes nesta pesquisa é o reconhecimento de que é necessário algum tempo para conseguirem que a reflexão seja produtiva. Igualmente, na pesquisa de Puchner e Taylor (2006), os professores valorizaram a reflexão sobre a prática e ficaram surpreendidos com o tempo que necessitavam para refletir e discutir questões relacionadas com a aula.

Numa pesquisa realizada no âmbito da formação inicial de professores, Burroughs e Luebeck (2010) indicam que os futuros professores tornaram-se mais críticos e reflexivos quando participaram numa atividade desse tipo. Essa experiência permitiu-lhes refletir sobre o trabalho que realizaram ao longo dos diversos momentos do estudo de aula. Lewis, Perry e Hurd (2009) referem resultados semelhantes, salientando que a reflexão conduziu à revisão dos planos de aula dos professores de modo a promover de forma mais eficaz o raciocínio dos alunos. Desse modo, constatamos serem várias as investigações que mencionam que os professores que se envolvem em estudos de aula se tornam mais reflexivos relativamente às suas práticas. Essa reflexão promove a alteração das tarefas propostas e uma maior valorização do raciocínio dos alunos.

\section{METODOLOGIA DE INVESTIGAÇÃO}

A metodologia de investigação seguida neste trabalho é qualitativa e interpretativa (Bogdan \& Biklen, 1994), tendo por base observação participante (JORGENSEN, 1989). A experiência decorreu no Agrupamento de Escolas da Lourinhã, situado numa região rural, a cerca de $80 \mathrm{~km}$ de Lisboa. Tendo ocorrido entre 3 de novembro de 2011 e 8 de fevereiro de 2012, envolveu cinco professoras do $1^{\circ}$ ciclo (Catarina, Carla, Fátima, Gorete, Purificação $\left.{ }^{3}\right)$, três que lecionam a $4^{a}$ série e duas do apoio educativo, pertencentes a três escolas do agrupamento, e uma equipe do Instituto de Educação da Universidade de Lisboa composta pelos quatro autores deste artigo.

$\mathrm{Na}$ nossa perspectiva, o estudo de aula deve estar nas mãos dos professores participantes. Assim, propusemos o desafio inicial para a sua realização e acompanhamos de perto as várias etapas do processo, não como quem o dirige a partir de uma posição superior, 
mas como quem participa na qualidade de consultor. O nosso papel foi, sobretudo, o de contribuir para que surgissem oportunidades de reflexão sobre as aprendizagens dos alunos e sobre as práticas por parte dos professores envolvidos. Antes de iniciarmos a experiência, reunimo-nos com uma das professoras do grupo e, durante a sua realização, participamos em várias reuniões na escola, com o grupo de professoras, bem como na observação da aula e na reflexão final.

A recolha de dados foi feita por quatro processos: (i) notas de campo, com registros da observação participante realizada nas reuniões na escola e na aula observada (NC); (ii) gravações de vídeo das sessões de planejamento (VP), da aula observada (VO), da reflexão pós-aula (VR) e de um seminário com outras escolas onde as professoras apresentaram a sua experiência (VS); (iii) reflexão escrita realizada pelas professoras participantes (R); e (iv) entrevistas semiestruturadas realizadas a três das professoras participantes (E). Dado o objetivo deste artigo, a análise de dados procura identificar elementos particularmente significativos do ponto de vista da aprendizagem profissional das professoras no que se refere às tarefas propostas e à atenção dada ao raciocínio dos alunos, bem como à sua visão da colaboração e da reflexão no âmbito profissional.

\section{A EXPERIÊNCIA}

De acordo com a estrutura habitual, este estudo de aula envolveu três momentos - planejamento, observação e reflexão e seguimento, que descrevemos nesta seção.

Planejamento. O primeiro passo deste estudo de aula foi propor o desafio de realizar um estudo de aula a uma das professoras do Agrupamento de Escolas, Gorete. A professora mostrou interesse e levou a sugestão para discussão numa reunião com os colegas, tendo sido bem-acolhida pelas professoras da $4^{a}$ série. O segundo passo foi a elaboração de uma proposta de calendário pela equipe do Instituto de Educação, contemplando o planejamento e a observação da aula e a reflexão pós-aula, que foi discutido e aperfeiçoado numa reunião realizada com Gorete (17 de novembro).

A fase de planejamento envolveu quatro sessões, realizadas entre dezembro de 2011 e fevereiro de 2012, cada uma com duração aproximada de uma hora e trinta minutos, que decorreram às quartasfeiras. A equipe do Instituto de Educação esteve presente em todas as sessões. A primeira sessão foi antecedida por uma reunião onde as professoras decidiram entre si o tópico a abordar - o conceito de ângulo. 
Na primeira sessão (em 7 de dezembro de 2011), as professoras começaram por fazer o reconhecimento geral do tópico no programa e nos manuais escolares. Em seguida, resolveram duas tarefas selecionadas pela equipe do Instituto de Educação, tendo procurado identificar, ao longo da sua resolução, possíveis dificuldades dos alunos, bem como sugerir alterações.

Na segunda sessão (em 4 de janeiro de 2012), discutiram um excerto de um artigo (MORAIS, CASCAIS \& PONTE, 2011), procurando destacar os momentos da aula referidos pelos autores. Posteriormente, a equipe do Instituto de Educação interveio, colocando questões e fazendo propostas. Nessa sessão as professoras decidiram também a tarefa a realizar pelos alunos e conceberam a sequência de aprendizagem em que esta se integraria (Figura 1).

$\mathrm{Na}$ terceira sessão (em 11 de janeiro), definiram-se, em conjunto, os segmentos previstos para a aula a observar e a sua duração aproximada. Outro ponto que ocupou bastante tempo foi a elaboração de uma tarefa de diagnóstico, a realizar previamente nas aulas das turmas das professoras envolvidas no estudo de aula.

A quarta sessão (em $1^{\circ}$ de fevereiro) iniciou-se com a reflexão sobre os resultados da aplicação da tarefa de diagnóstico, verificandose que a maioria dos alunos não sentiu dificuldades na sua resolução. Foi, então, que se definiu a turma e a professora que lecionaria a aula a observar. O estudo de aula foi programado para ser realizado numa turma da $4^{a}$ série, constituída por 12 alunos. A professora, Carla, tem cerca de 35 anos e trabalha com a turma desde a $1^{\text {a }}$ série. Durante a sessão, discutiu-se novamente a tarefa construída para a aula a observar e decidiu-se que o trabalho em sala de aula seria realizado em pares. Num momento posterior, discutiu-se o modo de apresentação da tarefa, as possíveis dificuldades dos alunos, as questões a sublinhar na síntese final e os processos de observação. Em relação a esse último aspecto, a equipe do Instituto de Educação propôs que, durante a introdução da tarefa e discussão e síntese final, os observadores se mantivessem no fundo da sala de aula, prestando atenção ao discurso geral e que, durante o trabalho de pares, cada um ficasse responsável pela observação de um par de alunos.

$\mathrm{Na}$ terceira sessão (em 11 de janeiro), definiram-se, em conjunto, os segmentos previstos para a aula a observar e a sua duração aproximada. Outro ponto que ocupou bastante tempo foi a elaboração de uma tarefa de diagnóstico, a realizar previamente nas aulas das turmas das professoras envolvidas no estudo de aula. 
1 - Tendo em conta que:

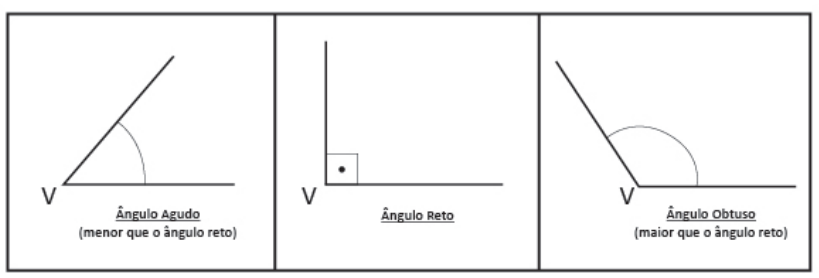

1.1 - Descobre se é possível construir um quadrilátero com as características definidas em cada situação, e registra as soluções encontradas.

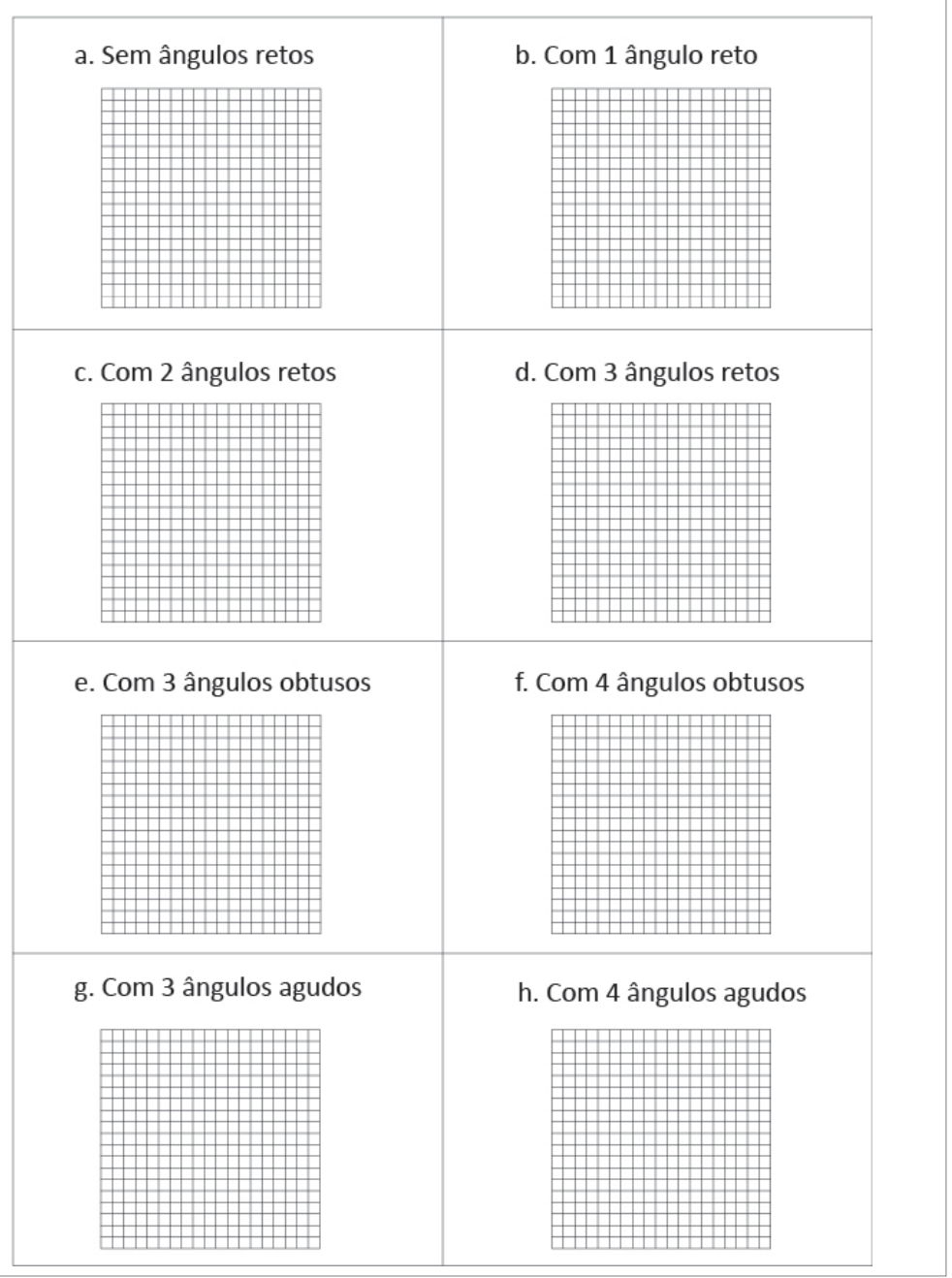

Figura 1 - Tarefa construída pelos professores sobre o conceito de ângulo.

Educação em Revista |Belo Horizonte |v.30|n.04 |p. 61 -79 | Outubro-Dezembro 2014 
$\mathrm{Na}$ terceira sessão (em 11 de janeiro), definiram-se, em conjunto, os segmentos previstos para a aula a observar e a sua duração aproximada. Outro ponto que ocupou bastante tempo foi a elaboração de uma tarefa de diagnóstico, a realizar previamente nas aulas das turmas das professoras envolvidas no estudo de aula.

A quarta sessão (em $1^{\circ}$ de fevereiro) iniciou-se com a reflexão sobre os resultados da aplicação da tarefa de diagnóstico, verificandose que a maioria dos alunos não sentiu dificuldades na sua resolução. Foi, então, que se definiu a turma e a professora que lecionaria a aula a observar. O estudo de aula foi programado para ser realizado numa turma da $4^{a}$ série, constituída por 12 alunos. A professora, Carla, tem cerca de 35 anos e trabalha com a turma desde a $1^{\text {a }}$ série. Durante a sessão, discutiu-se novamente a tarefa construída para a aula a observar e decidiu-se que o trabalho em sala de aula seria realizado em pares. Num momento posterior, discutiu-se o modo de apresentação da tarefa, as possíveis dificuldades dos alunos, as questões a sublinhar na síntese final e os processos de observação. Em relação a esse último aspecto, a equipe do Instituto de Educação propôs que, durante a introdução da tarefa e discussão e síntese final, os observadores se mantivessem no fundo da sala de aula, prestando atenção ao discurso geral e que, durante o trabalho de pares, cada um ficasse responsável pela observação de um par de alunos.

Observação. A aula observada (em 8 de fevereiro) teve a duração de 90 minutos. Os alunos entraram na sala e sentaram-se em pares. Em seguida, Carla introduziu a tarefa, recordando o assunto abordado na aula anterior. Os alunos mostraram-se interessados e começaram a trabalhar, enquanto a professora circulava pelas mesas e os observadores se deslocaram para junto do par a observar. Passados 40 minutos, a professora deu início à discussão coletiva, que se fez questão a questão, tendo os vários pares tido oportunidade de mostrar os quadriláteros que construíram. Para terminar a aula, Carla fez uma síntese e procedeu à recolha das folhas com as respostas dos alunos.

Reflexão e seguimento. Na reflexão sobre a aula observada (em 8 de fevereiro), a equipe do Instituto de Educação propôs que a discussão decorresse de acordo com a sequência de questões que compunham a tarefa, dando, sobretudo, atenção ao trabalho dos alunos em pares, uma vez que os observadores tinham registros bastante completos das ocorrências nessa fase. Em termos globais, as professoras consideraram que os alunos evidenciaram dificuldades na resolução de algumas questões da tarefa, tendo as questões sido amplamente discutidas, bem como diversas respostas dos alunos. 
Além disso, foi também discutido o que as professoras alterariam na tarefa. A essa primeira aplicação da tarefa, seguiu-se ainda no mesmo dia a sua realização por outras professoras do grupo, nas suas turmas.

\section{APRENDIZAGENS DOS PROFESSORES}

Consideramos, de seguida, as aprendizagens profissionais das professoras, começando por dois domínios da prática letiva - seleção das tarefas e atenção aos processos de raciocínio dos alunos - após o que abordamos a sua visão sobre o papel da colaboração e da reflexão.

Seleção de tarefas. $\mathrm{Na}$ fase de planejamento, coube às professoras selecionar a tarefa a realizar na aula a observar. Essa questão foi discutida em várias sessões, levando-as a repensar sua prática de seleção de tarefas para a sala de aula. Muito em especial deram particular atenção ao preconizado pelo programa de Matemática publicado pelo Ministério da Educação para este ciclo de ensino (ME, 2007). Na entrevista, Carla evidenciou essa ideia, referindo que a seleção da tarefa foi "uma etapa importante" que lhes permitiu "procurar" materiais "noutros livros" e em brochuras com várias tarefas desenvolvidas no âmbito do programa. De acordo com Carla, "se não fosse o estudo de aula", não conseguiriam selecionar uma tarefa "muito bem-desenvolvida" e não teriam consultado o programa da mesma forma. Também Fátima, na entrevista, nos deu conta que a tarefa selecionada vai ao encontro do preconizado "pelos novos programas e que $[\ldots]$ pode criar alguma ruptura com o que é a prática", tendo o estudo de aula dado um contributo importante nesse sentido.

O tipo de tarefa a propor aos alunos foi um outro aspeto que as professoras destacaram na sua reflexão escrita. $\mathrm{Na}$ sua perspectiva, o estudo de aula contribuiu para a seleção de tarefas apropriadas para a aprendizagem dos alunos, considerando que "a forma como todos os alunos, mesmo aqueles com mais dificuldades [...] se envolveram na procura de respostas aos desafios colocados" acabou por ser uma consequência do "resultado da aposta das docentes no desenvolvimento de atividades de cunho investigativo e exploratório" (R). Essa ideia foi, igualmente, salientada pelas professoras durante a apresentação que fizeram no seminário com outras escolas. Gorete referiu que o estudo de aula as despertou para a necessidade de realizar mais tarefas "de cunho investigativo e exploratório", de modo "a implicar mais os alunos no processo de aprendizagem" (VS). 
Também Carla referiu o potencial do estudo de aula, que possibilitou a construção de "outro tipo" de tarefas, de cunho "mais exploratório" e propiciadoras de modos "muito interessantes de [os alunos] conseguirem" resolver as questões (E). De fato, a professora assumiu, durante a entrevista, o interesse de propor na sala de aula tarefas exploratórias e mais desafiantes para os alunos.

Pelo seu lado, para Fátima, a tarefa do estudo de aula constituiu um "desafio" para os alunos, sendo uma tarefa "aberta", propiciando a partilha de ideias entre os alunos e a discussão de "vários tipos de resposta". Desse modo, na sua perspectiva, a aula deixou "de estar tanto centrada no professor" e passou "a estar mais centrada no aluno", permitindo "uma ruptura" com o que é habitual na sala de aula. Assim, considerou que os alunos estiveram "mais envolvidos" e conseguiram ser "construtores do próprio conhecimento" (E). Essa professora destacou, portanto, a seleção de uma tarefa que promoveu uma maior autonomia dos alunos, incluindo questões diferentes daquelas a que estavam habituados.

Desse modo, durante a fase de planejamento, as professoras procuraram selecionar e elaborar uma tarefa que possibilitasse aos alunos, através de um trabalho relativamente autônomo, explorarem o conceito de ângulo. Nas entrevistas, realizadas após o estudo de aula e no seminário, todas mencionaram o valor da preparação cuidadosa da tarefa, salientando a importância de mudar a natureza das tarefas a propor na sala de aula, com destaque para as tarefas de exploração.

Processos de raciocínio dos alunos. A participação no estudo de aula levou as professoras a estarem mais atentas e valorizarem mais os processos de raciocínio dos alunos. Isso pode ser observado ao longo de todo o trabalho. Durante o planejamento, tiveram oportunidade de discutir e refletir sobre as respostas dadas pelos alunos na tarefa diagnóstica. Esse momento foi bastante importante porque lhes permitiu preparar o caminho a percorrer, tal como menciona Fátima na entrevista: "a tarefa diagnosticou ao professor quais eram as dificuldades dos alunos $[\ldots]$ neste domínio", o que possibilitou uma reflexão mais fundamentada sobre a tarefa a realizar na aula $(\mathrm{E})$.

A esse respeito Gorete salientou que a discussão das respostas dos alunos, às questões da tarefa diagnóstica, permitiu "refletir no grupo [de professoras] as dificuldades" que os alunos tinham sobre o tópico e pensar sobre "a nova sequência de aulas" que antecederam a aula (E). De fato, após a discussão e reflexão sobre as respostas dadas pelos alunos, as professoras identificaram as dificuldades sentidas e tomaram decisões sobre a tarefa a propor. 
O momento da observação da aula e o da reflexão pósaula também concorreram para que os professores valorizassem os processos de raciocínio dos alunos. Fátima deu-nos conta disso quando mencionou que o grupo que observou procurou dar respostas às questões por tentativa e erro e os alunos "insistiam", "eram tão persistentes", "não queriam sair dali" e "estavam ali a tentar fazer, fazer" (E). Essa ideia foi também evidenciada pelas professoras na reflexão escrita. Na sua perspectiva, "os alunos encararam o desafio, revelando persistência e atitude de perseverança" (R).

$\mathrm{Na}$ reflexão escrita coletiva, as professoras mencionaram que o estudo de aula permitiu "acompanhar, com mais pormenor, a evolução do pensamento e as diferentes estratégias de resolução apresentadas pelos grupos de alunos ao longo da realização da tarefa" (R). A apresentação que fizeram no seminário com outras escolas transmitiu a mesma perspectiva. Por exemplo, Gorete valorizou o fato de o estudo de aula lhes ter possibilitado perceber a importância de "antecipar possíveis dificuldades e modos de atuação [dos alunos]". (VS)

Colaboração profissional. As cinco professoras definiram essa experiência como "benéfica para o desenvolvimento profissional" (R), destacando especificamente a importância do trabalho colaborativo realizado durante as sessões de planejamento. Para Carla, o estudo de aula permitiu colaborar com as colegas e "aprenderem muito umas com as outras" (E). Na sua perspectiva, só foi possível construir a tarefa para a aula a observar porque houve um verdadeiro trabalho em equipe. Indicou que nas sessões de planejamento puderam "discutir" e trocar ideias, "experiências" e "algumas situações [...] que se passam com os alunos" que as ajudaram a olhar para a sala de aula de outra "maneira" e a pensar qual "seria a melhor forma de abordar" o tópico (E). Para Carla, foi muito importante o pensarem "todas juntas", tendo-se criado um clima de confiança, onde se sentiram "à vontade" para colocar dúvidas e questões (E). Nas suas palavras, foi notório o papel fundamental que a partilha e a discussão de ideias tiveram na superação das dificuldades que surgiram no planejamento da aula. Nota-se que esse grupo colaborativo proporcionou um sentimento de confiança a essa professora que reconheceu que antes dessa experiência nunca tinham trabalhado em conjunto $(\mathrm{E})$.

Igualmente, para Fátima, trabalhar colaborativamente foi uma "troca" que permitiu o enriquecimento mútuo. Mais uma vez, ressaltou a importância de partilhar ideias e de comparar experiências tendo em vista a melhoria da prática. $\mathrm{Na}$ entrevista, essa professora afirmou que o trabalho em equipe as levou a "experimentar" 
uma situação nova, tendo sido fundamental o apoio que sentiram dos vários elementos do grupo. $\mathrm{Na}$ sua perspectiva, o trabalho colaborativo permitiu "construir qualquer coisa em conjunto [...] e neste sentido a experiência do estudo de aula foi muito profunda" (E). Suas palavras revelaram que houve um compromisso de todas as professoras envolvidas, possibilitando a concretização do estudo de aula, que envolveu uma análise conjunta de várias situações. Assim, a colaboração que se desenvolveu no âmbito dessa experiência levou Fátima a reconhecer que houve um aumento da confiança, levando as cinco professoras a arriscar e experimentar novas situações.

A esse propósito, na entrevista, Gorete ressaltou que o estudo de aula possibilitou a partilha de ideias e a definição de um objetivo comum. Na sua perspectiva, à medida que as sessões de planejamento foram decorrendo, "sentiu-se que houve uma melhor partilha, uma melhor coesão e um maior trabalho para o mesmo objetivo", havendo uma evolução no modo como trabalharam em conjunto. Segundo referiu, no início, como nunca tinham formado um grupo de trabalho, houve algumas dificuldades na partilha de experiências. No entanto, à medida que as sessões avançaram, o grupo foi-se unindo, criouse um clima de confiança, perderam-se "os receios de abrir a sala" de aula e puderam-se explicitar, sem medos, as dificuldades sentidas (E). A descrição de Gorete permitiu perceber que o estudo de aula possibilitou, ao longo das sessões, a criação de uma dinâmica de trabalho colaborativo valorizada por todas as professoras envolvidas.

$\mathrm{Na}$ reflexão escrita, as professoras voltaram, mais uma vez, a ressaltar a importância de partilhar ideias e de comparar experiências tendo em vista a melhoria da prática. Assim, os aspetos que destacaram dessa experiência como mais significativos do ponto de vista formativo "foram o trabalho colaborativo entre professores, a partilha e troca de saberes e de diferentes estratégias para facilitar a compreensão da tarefa" (R). Desse modo, todas as professoras consideraram que o estudo de aula promoveu a colaboração, estando sempre presente o apoio e a ajuda entre os vários intervenientes. Durante todo o processo, foi possível criar um ambiente de confiança que lhes permitiu exprimir suas dúvidas e seus receios sem constrangimentos.

Reflexão. O estudo de aula possibilitou às professoras refletir sobre sua própria prática. De acordo com as suas palavras, a realização do estudo de aula criou uma situação de investigação, ação e reflexão que as levou a "encontrar novas alternativas para aperfeiçoar a antecipação de possíveis dificuldades dos alunos no processo de ensino e aprendizagem, apontando possíveis soluções" (R). 
Ademais, reconheceram que "a reflexão em conjunto para prever possíveis e eventuais dúvidas e/ou reações dos alunos, a discussão das várias etapas de resolução da tarefa permitiram um enriquecimento mútuo quer ao nível do desenvolvimento de boas práticas, como ao nível pessoal" (R). Desse modo, o estudo de aula levou as professoras a valorizar a reflexão, destacando-se o modo como passaram a refletir sobre as dificuldades dos alunos e as possíveis respostas nas tarefas.

$\mathrm{Na}$ entrevista, Carla referiu um conjunto de questões que orientaram algumas das reflexões do grupo: "O que é que podemos fazer?", "O que é que podemos responder?", "Como é que os podemos obrigar a pensar?”. Essas questões estão eminentemente ligadas à prática e ajudaram as professoras "a preparar de como é que [poderiam] reagir" a várias situações na sala de aula (E). Igualmente fundamentais para promover um clima propício à reflexão, foram as interações que ocorreram no grupo de trabalho que, como menciona Gorete na entrevista, as obrigou "a refletir sobre as práticas" e trouxe "uma nova visão acerca das coisas que [não estavam] acostumadas". Esse refletir de modo mais aprofundado permitiu-lhes "opinar de uma forma mais construtiva e muito mais implicada nas escolhas que foram feitas" (E). Desse modo, as professoras consideraram que essa experiência possibilitou a reflexão sobre a prática, tendo a interação entre os vários intervenientes dado um forte contributo para o desenvolvimento da sua capacidade reflexiva.

\section{CONCLUSÃO}

Este trabalho permite perceber que o estudo de aula é um processo de formação de professores que tem potencialidades para promover diversas aprendizagens no âmbito da prática letiva, nomeadamente relacionadas com a seleção de tarefas e os processos de raciocínio dos alunos. Esses resultados vêm corroborar os obtidos em diversas pesquisas anteriores (HART \& CARRIERE, 2011; MURATA et al., 2012; SACK \& VASQUEZ, 2011), reforçando a ideia de que os estudos de aula podem proporcionar aos professores um olhar mais atento sobre a natureza das tarefas a propor em sala de aula e os processos de raciocínio dos alunos. Com efeito, as professoras reconheceram a importância de mudar o tipo de tarefas a propor, passando a valorizar mais as tarefas de exploração e a ter em consideração que, antes da sua introdução 
na sala de aula, é necessário um planejamento cuidadoso e aprofundado. O enfoque na valorização do raciocínio dos alunos, à semelhança de pesquisas anteriores (LEWIS, PERRY \& HURD, 2009; ROBINSON \& LEIKIN, 2012), possibilitou repensar as tarefas a desenvolver, identificar suas possíveis dificuldades e elaborar estratégias mais eficazes para as ultrapassar.

Este trabalho também coloca em evidência o contributo do estudo de aula para o desenvolvimento de relações de trabalho colaborativo e da valorização da reflexão por parte dos professores. $\mathrm{Na}$ verdade, esse processo de formação encorajou as professoras envolvidas a arriscar situações novas na sua sala de aula, que só foi possível porque trabalharam colaborativamente. Essa experiência proporcionou-lhes um ambiente seguro, que lhes permitiu explicitar dúvidas e questões sem constrangimentos. Diversas pesquisas anteriores também vão no mesmo sentido, como é o caso do trabalho de Robinson e Leikin (2012), onde o trabalho colaborativo, promovido durante o estudo de aula, ajudou os professores a compreenderem a necessidade de alterar as suas práticas e discutirem soluções. Este estudo de aula contribuiu ainda para a valorização da reflexão pelos professores. Essa reflexão surgiu a partir da interação com os outros colegas e com a equipe do Instituto de Educação. Também a pesquisa de Puchner e Taylor (2006) evidencia que a participação nesse tipo de atividades possibilita o desenvolvimento da reflexão dos professores.

De fato, o modo como correu essa experiência e as reflexões realizadas pelas professoras permitem-nos afirmar que o estudo de aula, envolvendo a preparação aprofundada de uma aula, a sua observação e a reflexão posterior, constitui um significativo processo de desenvolvimento profissional. Daqui decorre a necessidade de os professores envolvidos adotarem a "lente de investigador", que lhes permite aprender a colocar questões, saber preparar as aulas que respondem às questões colocadas e procurar evidências na aula que as clarifiquem (FERNANDEZ, CANNON \& CHOKSHI, 2003, p. 182). O presente trabalho também mostra que as aprendizagens dos professores se relacionam de modo muito forte com o enfoque seguido na respectiva realização, que nesse caso deu importância especial às tarefas a propor e à antecipação dos raciocínios dos alunos e das respectivas dificuldades. Por isso, é importante estudar as condições de realização de estudos de aula, tendo em vista as aprendizagens profissionais dos professores participantes que se procura promover. 


\section{REFERÊNCIAS}

BOGDAN, R., \& BIKLEN, S. Investigação qualitativa em educação: Uma introdução à teoria e aos métodos. Porto: Porto Editora, 1994.

BURROUGHS, E., \& LUEBECK, J. Pre-service teachers in mathematics lesson study. The Montana Mathematics Enthusiast, 7(2/3), 391-400, 2010.

CORCORAN, D., \& O'REILLY, M. Learning from lesson study: Power distribution in a community of practice. In C. SMITH (Ed.). Proceedings of the British Society for Research into Learning Mathematics, 31(1), 55-60, 2011.

DOIG, B., GROVES, S., \& FUJII, T. Lesson study as a framework for preservice teachers' early field-based experiences. In: L. HART, A. ALSTON, \& A. MURATA (Eds.). Lesson study research and practice in mathematics education (pp. 181-200). Dordrecht: Springer, 2011.

FERNANDEZ, C., CONNON, J., \& CHOKSHI, S. A US-Japan lesson study collaboration reveals critical lenses for examining practice. Teaching and Teacher Education, 19, 171-185, 2003.

FERNANDEZ, M., \& ZILLIOX, J. Investigating approaches to lesson study in prospective mathematics teacher education. In: L. HART, A. ALSTON, \& A. MURATA (Eds.). Lesson study research and practice in mathematics education (pp. 85-102). Dordrecht: Springer, 2011.

HART, L., ALSTON, A., \& MURATA, A. (Eds.) Lesson study research and practice in mathematics education. Dordrecht: Springer, 2011.

HART, L., \& CARRIERE, J. Developing the habits of mind for a successful lesson study community. In: L. HART, A. ALSTON, \& A. MURATA (Eds.), Lesson study research and practice in mathematics education (pp. 27-38). Dordrecht: Springer, 2011.

JORGENSEN, D. L. Participant observation: A methodology for human studies. Newbury Park, CA: Sage, 1989.

LEWIS, C., PERRY, R., \& HURD, J. Improving mathematics instruction through lesson study: A theoretical model and North American case. Journal of Mathematics Teacher Education, 12, 285-304, 2009.

MEYER, R., \& WILKERSON, T. Lesson study: The impact on teachers' knowledge for teaching mathematics. In: L. HART, A. ALSTON, \& A. MURATA (Eds.), Lesson study research and practice in mathematics education (pp. 15-26). New York, NY: Springer, 2011.

MINISTÉRIO DA EDUCAÇÃO (2007). Programa de Matemática do Ensino Básico. Lisboa: Ministério da Educação, 2007.

MORAIS, A., CASCAIS, C., \& PONTE, J. P. O trabalho com sequências numa turma do $1^{\circ}$ ano de escolaridade. In: Atas do XXII SIEM. Lisboa: APM, 2011.

MURATA, A. Conceptual overview of lesson study. In: L. HART, A. ALSTON, \& A. MURATA (Eds.). Lesson study research and practice in mathematics education (pp. 1-12). Dordrecht: Springer, 2011.

MURATA, A., BOFFERDING, L., POTHEN, B., TAYLOR, M., \& WISCHNIA, S. Making connections among student learning, content, and teaching: Teacher talk paths in elementary mathematics lesson study. Journal for Research in Mathematics Education, 43(5), 616-650, 2012.

PUCHNER, L., \& TAYLOR, A. Lesson study, collaboration and teacher efficacy: Stories from two school-based math lesson study groups. Teaching and Teacher Education, 22, 922-934, 2006.

ROBINSON, N., \& LEIKIN, R. One teacher, two lessons: The lesson study process. International Journal of Science and Mathematics Education, 10, 139-161, 2012. 
SACK, J., \& VASQUEZ, I. The intersection of lesson study and design research: A 3-d visualization development project for the elementary mathematics curriculum. In L. HART, A. ALSTON, \& A. MURATA (Eds.). Lesson study research and practice in mathematics education (pp. 201-220). Dordrecht: Springer, (2011).

SAITO, E., HARUN, I., KUBOKIC, I., \& TACHIBANAD, H. (2006). Indonesian lesson study in practice: Case study of Indonesian mathematics and science teacher education project. Journal of In-service Education, 32(2), 171-184, 2006.

\section{NOTAS}

${ }^{1}$ Em inglês, lesson study e, em japonês, jugyokenkyuu.

${ }^{2} \mathrm{O}$ que corresponde aos quatro primeiros anos do Ensino Fundamental.

${ }^{3}$ Nomes reais das professoras que assumiram a sua vontade de serem identificadas como as protagonistas deste estudo de aula.

Recebido: 29/06/2013

Aprovado: 01/10/2014

Contato:

Universidade de Lisboa Instituto de Educação da Universidade de Lisboa Alameda da Universidade Lisboa | Portugal 1649-013 
